\title{
The special issue for tropical disease research: a tool to disseminate research results for more effective disease control
}

Hussein A. Gezairy, ${ }^{1}$ MD, FRCS

\section{Introduction}

Infectious and parasitic diseases continue to prevail as the major causes of morbidity and mortality in developing countries. In the Eastern Mediterranean Region (EMR) of the World Health Organization they contribute to one-third of annual deaths and $32 \%$ of disease burden as measured in disability-adjusted life years [1,2]. These are considered the measurable rates of the disease burden in the EMR. On the other hand, the indirect burden of these diseases has been greatly underestimated in this Region. This includes the economic and social burden, and the impact of these diseases on the quality of life and productivity of afflicted individuals. In this context, such burden could be regarded as an impediment to progress and development of EMR countries.

Thus, developing countries are faced with an overwhelming array of health problems and yet have limited resources to deal with them. To help plan strategies to tackle these problems, information based on the global health situation provides limited guidance; a developing country's priorities must be based primarily on health information and research done in and by each country.
From this perspective, the Commission on Health Research for Development has pointed to the critical importance for all countries to have the capacity to carry out research needed to define their own health problems and to work out affordable solutions for these problems [3]. Such health research requires multidisciplinary expertise, particularly involving skills in epidemiology, biostatistics and social sciences.

In order to enhance the expertise needed to conduct research, the UNICEF/ UNDP/World Bank/WHO special programme for research and training in tropical diseases (TDR) has been strengthening the research capacity in disease endemic countries since 1978 [4,5]. In 1992 the WHO Regional Office for the Eastern Mediterranean (EMRO) initiated the small grants scheme for operational research in tropical diseases in order to improve the overall weak research capacity in the Region, promote research activities and support research contributing to the prevention and control of communicable diseases. This scheme initially used a contribution of Arab funds and later was supported by EMRO and TDR.

It was thereafter recognized that active contribution of national disease control

${ }^{1}$ Regional Director for the Eastern Mediterranean.

المجلة الصحية لشرق المتوسط، منظمة الصحة العالمية، المجلد التاسع، العدد ع، ب... 
programmes in conducting research was crucial to identifying key research questions and, more importantly, translating research results into practice. Accordingly, in the year 2000, involvement of the national disease control programme in the research team was considered an essential criterion for eligibility for funding a project.

\section{Research areas}

This special issue includes 29 articles originating from projects supported over two rounds of the small grants scheme (20002001) and implemented during the period 2001-2002. The research areas funded by the scheme in this period vary from descriptive epidemiological studies filling information gaps to evaluation of new diagnostic techniques, interventions or public health policy in the field of tropical diseases.

\section{Descriptive studies}

The problem of leishmanisais was investigated and information was gathered about the distribution and burden of visceral leishmaniasis in Gedaref State, Sudan, and risk maps that could predict disease burden in other endemic areas were produced. In addition, a new focus for zoonotic cutaneous leishmaniasis was identified in Sabzevar in the north-east of the Islamic Republic of Iran.

The determinants of contracting malaria and its mortality among displaced populations as well as the determinants of complicated malaria and its mortality in hospitalized patients were studied in Sudan. Similar to the maps produced for leishmaniasis, a surveillance map for malaria was developed in Egypt. Molecular entomological studies investigated vector species for malaria, mainly from the Islamic Republic of Iran.
As regards tuberculosis, the risk factors of treatment failure for tuberculosis patients were examined in a study from Egypt, and the alarming high prevalence of this disease in juvenile prisons is reported from Pakistan. Evidence about the nonadherence of the private sector to the national tuberculosis control guidelines in the management of tuberculosis patients is reported from three countries: Islamic Republic of Iran, Pakistan and Somalia. Gender differences in health-seeking behaviour and tuberculosis control were also investigated in a multicountry study involving Egypt, Pakistan and the Syrian Arab Republic.

\section{Evaluation of new diagnostic tools and drug studies}

The diagnostic performances of KATEX and rK39 tests for visceral leishmaniasis were studied in Sudan and the Syrian Arab Republic respectively. Rational prescription of antimalarial drugs was examined in studies from Yemen.

\section{Evaluation of new interventions}

Evaluation of vector control methods included: insecticide impregnated dog collars for visceral leishmaniasis in the Islamic Republic of Iran, and larvivorous fish and neem extract for malaria in Somalia and Egypt respectively. In addition, a comparison of three different larvicidal strategies (varying regimens of Abate) was carried out in Oman. The effect of the involvement of a nongovernmental organization and routine home visiting by trained personnel on the compliance and treatment outcome of tuberculosis patients and late comers respectively were studied in Iraq.

\section{Evaluation of public health policy}

Evidence about the success of the current public health strategy of mass administra-

المجلة الصحية لشرق المتوسط، منظمة الصحة العالمية، المجلد التاسع، العدد ع، ب... 
tion of diethylcarbamazine/albendazole in eliminating lymphatic filariasis is reported from Egypt.

\section{Research and war}

In spite of the onset of war in Iraq, researchers there succeeded in completing two projects. The first was a propsective study on a cohort of schoolchildren with positive tuberculin skin tests and their household contacts, and the second was an evaluation of the knowlegde, attitudes and practices of patients and health care workers regarding tuberculosis. In this context, it needs to be mentioned that the lack of communication resulting from the conflict deprived the research team of the technical support by EMRO. For this and numerous other reasons, war has a considerable negative impact on the progress and develpoment of the afflicted countries.

\section{WHO's role}

WHO has played, and should always play, a major role in coordinating the small grants scheme in order to ensure the relevance of the topics investigated to disease control and the reliability of the results. Technical support in scientific writing was also provided in order to disseminate the research results to the international scientific community and health policy-makers in disease-endemic countries, and to increase the scientific contribution of the Region to indexed journals. It is a source of pride that a considerable number of these studies were carried out by minsitry of health per- sonnel, i.e clinicians rather than academic staff dedicated to research. This is attributed to the recent change in focus of the small grants scheme from supporting only academic researchers to supporting all health care providers. As a result of this strategy, the research culture has been strengthened in many control programmes of the ministries of health, and this has ensured that the right questions have been posed and answered.

\section{Conclusion}

By compiling this special issue of EMHJ, we aimed to disseminate information to both health care providers and, in particular, to health policy-makers. Therefore, health policy-makers in disease-endemic countries are urged to make use of the information published in this issue for more effective disease control.

The different topics covered in the two rounds of the small grants scheme are well reflected by the contents of this issue. Included also are four invited reviews from international experts on the four diseases covered (filariasis, leishmaniasis, malaria and tuberculosis). We wish to express our sincere gratitude to all of them for their invaluable contribution.

We hope that this issue will be a truly valuable resource for all those interested in the control of tropical diseases, and that the information and tools generated will be used for cost-effective control of these diseases to alleviate human suffering in our Region and other endemic countries.

\section{References}

1. The work of WHO in the Eastern Mediterranean Region: annual report of the Regional Director, 1 January-31 Decem- ber 2003. Cairo, WHO Regional Office for the Eastern Mediterranean, 2004.

المجلة الصحية لشرق المتوسط، منظمة الصحة العالمية، المجلد التاسع، العدد ؟، ب... 
2. DCD Division of Communicable Disease Control: annual report 2002. Cairo, WHO Regional Office for the Eastern Mediterranean, 2003 (WHO-EM/DCD/ 003/E/G) (http://www.emro.who.int/tdr/ DCDAnnualReport02.pdf).

3. When the poor need food, who needs research? How Essential National Health Research can lead to better health, greater equity. Geneva, Council on Health Research for Development
(COHRED), 1999 (http://www.cohred.ch/ cgi-bin/cohred).

4. Morel CM. Reaching maturity -25 years of the TDR. Parasitology today, 2000, 16(12):522-8.

5. Remme JH et al. Strategic emphases for tropical diseases research: a TDR perspective. Trends in microbiology, 2002, 10(10):435-40.

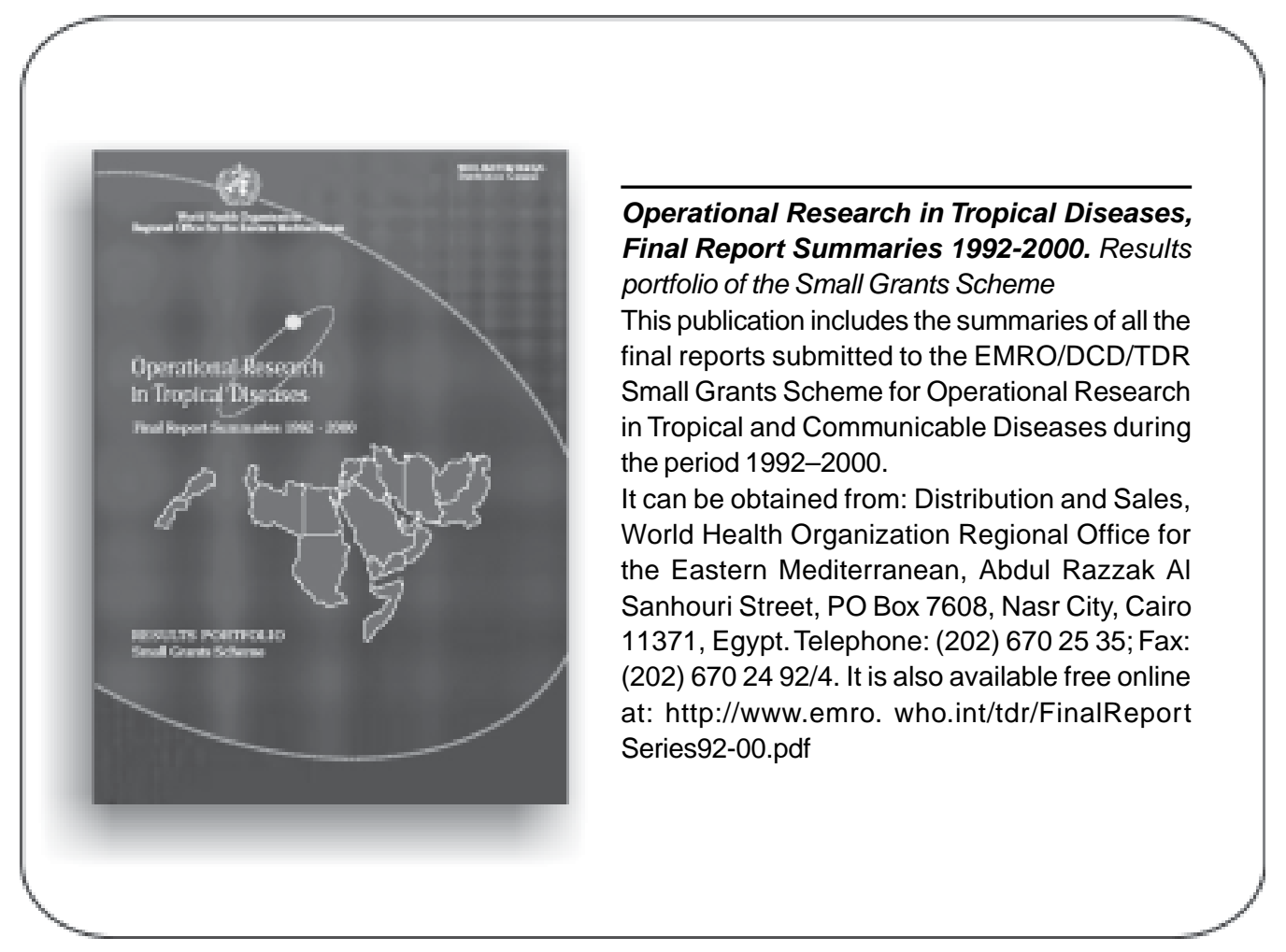

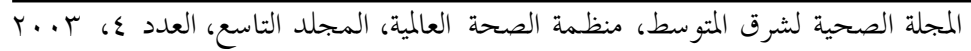

